\title{
Research on Application of Games in Pre-School Music Education
}

\author{
Shan $\mathrm{HaO}^{1}$ \\ ${ }^{1}$ Xi'an University, $\quad$ Xi' an, Shaanxi, 710065
}

\section{KEYWORDS: Application; Games; Pre-School Music Education}

\begin{abstract}
With the progress and development of society, people recognize the value of arts education in the deepening of early childhood music education is increasingly subject to people's attention. 3-6 years old children in a particular age, their psychological and physiological are in its infancy, very imperfect state. Therefore, we cannot use in older children and adults education to educate them. At this stage of the children have their own way of learning. In early childhood music education in how to train according to the psychological and physiological characteristics of children children's interest in music, foster children to music sensibility, expression and creativity; how to further stimulate young children active learning; what kind of learning and teaching methods to meet this series of questions needs children brought to our broad thinking.
\end{abstract}

\section{Introduction}

Since China's reform and opening, especially in recent years, early childhood education has been rapid development. The central Ministry of Education in "Kindergarten Education Outline", clearly states: "The game is children basic life activities, games occupies an extremely important role in the whole early childhood, it is advantageously carried out physical, intellectual, moral, and aesthetic development of education. It means "the State Education Commission issued in June 1989," nursery work order "(draft) and issued June 1, 199620 Decree stressed that:" Kindergarten should be to the game as the basic activities, the game is for young children comprehensive education important form. It is visible that games and early childhood education has a relationship cannot be divided up. Through the initial quest for game interaction and early childhood music education theory and practice, trying to confirm the game and early childhood music education activities close relationship, but also an effective way to the development of early childhood music education today, looking for useful insights on early childhood music education activities, explore strategies to play-based early childhood music education activities, and thus solve some problems in early childhood music education activities exist.

\section{The Classification and Features of Educational Games}

From the above discussion of the basic concepts of the game can be found in the concept of the game is more complex and diverse. Different standards division of game species selected according to their classification, the type of game is also different. "From the point of view of the degree of social division, the game can be divided into idle games, alone games, watch the games, parallel games, games and joint cooperation game; divided from the perspective of cognitive development, the game can be divided into functional games, construction of the game, pretend games and rules of the game; the game purpose of classification, playgroup main creative games, educational games and game play for the game kind of division of different people from different angles to cut, there 
will be a different classification results author. View from the discipline of the game reflected the perspective of division can be divided into math games, music, games, art games, science games. Games can also be divided through various angles, limited space, not in this discussion.

Huang Chung people mentioned in his book "pre-school" in the children's game of educators will be summarized in the following four characteristics representative: "First, the game is active voluntary activity of children; second, the game is in the illusion scenario reflects life around; third, the game is no practical value to society, there is no mandatory obligation to society, does not directly create wealth; fourth, the game along with the pleasant mood .14 "through the above four features in-depth understanding, the author's own research study concluded that children can learn more game summed up the following characteristics:

Each game contains fun and fun is a necessary condition for the game is also the inherent characteristics of the playgroup. It is not a strong sense of purpose as the goal, attention to experience the process. The reason why children interested in the game, because the interesting features of the game to bring pleasure to children physically and mentally relaxed feeling, this feeling strongly attracted children spontaneously added to the activities in order to acquire knowledge and from activities. Unlike labor game, To create wealth for the main purpose of the study is also different, with a mandatory feature. It is only associated with children of their own interest, active participation of young children. The main purpose of the game is to include direct access to physical and mental pleasure. The reason why children love the game is very popular, because children get a lot of pleasant relaxing mood in the game. Because young children during the game are not the pursuit of clear objectives, no psychological pressure and burden, therefore, consume less energy. So the game has a strong direct interest, so in the game with a total preschool pleasant emotional experience. The original meaning of the game is that the children in the game to get some pleasure, if not because of their children's interest and direct the game, then the game will lose its original meaning.

\section{Musical Elements Analysis Included in the Game}

As the most primitive rhythm of the music and the most basic elements, he is the most active element of the music of the most common, and therefore most apparent in the course of music, rhythm relatively easy to detect and young children. Therefore, we should actively encourage children in a music game by rhythmic feel of memory, and gradually formed its own inner rhythm. Overview playgroup written and practical cases found that rhythmic elements playgroup included accounted for the vast proportion of all the music elements. From early childhood game of percussion games, rhythm games, listen to distinguish the game, able to reflect the language of rhythm training.

For example: Squad quiz "in the park what flower" (spectra 3-1), the teacher before the game to show the rhythm pattern, according to the teacher to show pictures of different colors, children answered with songs. A seemingly simple common quiz answer repeated by children, they UX this type have a better grasp of rhythm.

All through the game, children can feel happy rhythm change phenomenon. Teachers cleverly use the dialogue game play, so that children involved. Teachers show examples of a different color picture, the child repeatedly in answer to the rhythm pattern $U$ X have a better grasp. In the Examples II teachers to use children to imitate the psychological, so that children are familiar with the rhythm of the music in the show. I viewed numerous textbooks and case analysis found that the rhythm of the music elements can experience a variety of children games, and throughout the course 
of the game. Therefore, teachers should create more games that appeal to young children, give them interesting rhythm experience.

Rhythmic activities generally contain rhythm, dance rhythms and other activities of the three aspects. Rhythm activity is one of children's favorite music events and is one of the pre-school education of children is the most important and most widespread means of education. In ordinary life we find that some of the children to hear their favorite music melody will naturally follow the music and dancing, the music of this phenomenon shows that children have a natural intuition impromptu response. They use body demonstrated his special feeling for the music and understanding. Rhythmic coordination of activities in children's emotional regulation, aspects of the action, imagination creativity have played a multifaceted role in developing early childhood music performance beauty and feel the beauty.

In musical terms, the melody can also be called the tune, it is by undulating sound continuously formed, after processing at the time of conception were organized. In a piece of music, the melody of the diverse composition of the different pitches upstream, downstream or in parallel, and so on. Kinder music melody works in general is relatively simple, in a young child's grasp of melody and memory. We often find that children spontaneously hum the first few songs, some from these kindergartens, some exposed to in life. However, these are only small part melody music teachers or parents consciously teach. The observation that, playgroups inseparable from music, music education, if not for the purpose of music games will usually use music as a background, add color to children activities.

Music called intensity level strength, it is usually with the performance of the music content are closely linked. Music performance content up passionate, militant, generally it will be a strong force. And like a lullaby, lullaby like music, its efforts will be weak. For the children of this strength is sufficient capacity to divide, such as: do exercise in the morning when the play "athletes march", children will show exciting mood; nap when playing "Lullaby", the child will calm down, go to sleep status. The performance of these children is in fact derived from the grasp of the intensity of the music. In the game, the intensity of the musical mastery of children completes the game or not plays a considerable role.

Music musical form known as lateral organizational structure, it is clear that this concept is the ability for children to understand there is a certain difficulty. So, I think, in the teaching process through way of the game, to guide children to learn the basic elements of music, cleverly designed way to help children recognize and learn the structure and composition of music. In teaching children, most of the music for a musical form that body section, this refined musical short, relatively easy to grasp.

Some color tone sounds and instrument sounds of the points. Voice Training for Children is also an important part of early childhood music education discrimination. Teachers will be to improve the ability to identify children on the sound by listening to distinguish the game. A hearing in the game "Listen to the Voice edited rhythm," teacher treble rhythm instruments (eg triangle, a small bell), the tenor of rhythm instruments (such as tambourine), the bass rhythm instruments (such as drums) and win by a quarter notes quaver rhythm and composition. Children of the teacher's presentation clapping respectively, hide feet high motor performance musical instrument, music, and bass. Again auditory games "Listen to the Voice", respectively, to imitate old teacher, parents and children sound performance bass, midrange and treble. Children were used to clapping, shaking his head and shoulder movements wins to show their voices heard.

Speed is very important in a music musical elements, the composer can work to express emotion through music speed. Also on the pace early childhood understanding of music and memory plays 
an important role. Activities such as large classes "brave rabbit", music teachers through the rabbit (slightly faster, live call) and wolves music (slower, deep), guide children to discern game animal images. When the rabbit music appears followed by live call, children learn to do a faster speed rabbit action. When the wolf appeared music, children follow a low slower pace to learn the wolf action, according to the rhythm of half notes, dragging a heavy pace, fiercely walk. Children in the game it is to identify the performance of the music content through the grasp of the song speed.

\section{Conclusion}

Playgroup is based on original children's life experiences and knowledge in order to promote children growing up happy in the learning activities are mainly educational purposes. This is not the game will be divided into two distinct and learning activities, in fact, children play and learning are mutually reinforcing. Playgroup promotes early childhood learning music knowledge, on the contrary, knowledge of music and themes for young children to bring the game to enrich the diversity of the game change. So, today's kindergarten teachers should let children into the main teaching activities try teaching the game as the basic activities of early childhood music education. Playgroup due preclude the use of adapted physical and psychological characteristics of children education, in practice, often receive good results.

\section{Reference:}

[1] Wang Chen. The new concept of curriculum development based music game teaching [J] World of Music, 2006, (6): 16-17.

[2] Lin Chong. Susie Games Music and Games [J] musical life, in 2005, (6): 38-39.

[3] Wang Feng. Music game - Classroom vitality agent [J] Primary and Secondary Music Education, 2002, (11): 21.

[4] Ma Wenchun. Experiences organization music game [J] Shandong Education, 1999, (18): 25.

[5] Indian music plays games and social development of pre-school children [J] Shandong Education, 1999, (27): 16-17.

[6] Maxin Zhi, Sun Jie. "Finger music game" Design and Analysis [J] early childhood education, 1993, (11): 15. 